\title{
Do outro lado do mar: uma representação do Brasil em Desamparo, de Inês Pedrosa
}

Mauro Dunder

Universidade Federal do Rio Grande do Norte

\begin{abstract}
Resumo
O presente artigo visa a discutir como se dá a representação dos brasileiros no romance Desamparo (2015), da portuguesa Inês Pedrosa. Por meio de uma leitura da obra, apontar-se-ão as principais características que o romance atribui às personagens, aproximando-as ou distanciando-as dos diversos estereótipos que rondam a imagem e a autoimagem do brasileiro, a fim de concluir qual a imagem do Brasil e dos brasileiros a autora oferece aos seus leitores.
\end{abstract}

Palavras-chave: Desamparo; Inês Pedrosa; representações do brasileiro.

\begin{abstract}
This article aims at discussing how Brazilians are portrayed by Portuguese writer Inês Pedrosa, in her novel Desamparo (2015). The reading of the novel will show the main characteristics of the characters, approaching them or distancing them from the diverse stereotypes which surround the image and the self-image of Brazilians offered by the author to her readers.
\end{abstract}

Keywords: Desamparo; Inês Pedrosa; representation of Brazilians.

Recebido em: 08/08/19

Aprovado em: 16/11/19

Por motivos óbvios, portugueses e brasileiros têm uma espécie de curiosidade recíproca: nas duas culturas, é possível encontrar manifestações em que se caracterizam, quase sempre de maneira estereotipada, os povos desses dois países. Se os portugueses são "burros", no Brasil, os brasileiros são "malandros” em Portugal.

Já na literatura portuguesa do século XIX, é comum encontrarem-se referências aos "brasileiros". Em geral, o uso desse termo apontava para um português retornado, ou para um descendente de portugueses nascido no Brasil, depois de ter se aventurado economicamente na antiga colônia, quase sempre denunciando envolvimento com o tráfico de escravos. É exemplo dessa caracterização o burguês Castro Gomes, de Os Maias (1888), de Eça de Queirós.

Apesar de uma história comum, Portugal e Brasil ainda se veem com algum estranhamento. Afinal, como afirma Luiz Ruffato, escritor brasileiro, em artigo publicado em Público, em abril de 2015: "Falar a mesma língua não é partilhar a mesma cultura." 
Nesse sentido, no mesmo artigo, Inês Pedrosa declara, sobre a presença do Brasil em suas obras, em especial sobre essa presença em Desamparo, seu então mais recente romance:

É sempre um perigo. Passo a vida a ler coisas sobre as relações entre Portugal e o Brasil, mas é difícil a uma pessoa de um país escrever sobre outro. Corre-se o risco do exotismo e do pitoresco. [...] Mas interessa-me brincar com isso e com a sintaxe e como tenho uma relação próxima atrevo-me. (LUCAS, 2015)

A obra de Pedrosa, como o próprio nome anuncia, tem o sentimento como protagonista. Diversas narrativas entrelaçam-se, todas elas pautadas por alguma forma de abandono, traição ou perda amorosa que acaba desaguando no desamparo do título. Raul, personagem nuclear no romance, é um arquiteto brasileiro que mora em Portugal. Sua mãe, Jacinta, é uma portuguesa que foi levada pelo pai para o Brasil aos três anos de idade, onde viveu por mais de cinquenta anos, tendo voltado a Portugal para cuidar da mãe idosa. Como consequência disso, diz Jacinta:

No Brasil eu sempre fui a Portuguesa; em Portugal, passei a ser a Brasileira — está lá no caderninho da conta da mercearia do meu primo Zé Paulo, que não me deixa faltar nada porque sabe que eu pago: não está Jacinta Sousa, está escrito "Brasileira". (PEDROSA, 2015, p. 23)

Ao dizer que, no Brasil, "eu sempre fui a Portuguesa", e que, em Portugal, "passei a ser a Brasileira", Jacinta exemplifica o fato de que vive em uma espécie de "não lugar" identitário, uma vez que sua personalidade não é exatamente marcada pela vivência em um ou em outro lugar, mas sim por uma espécie de amálgama das duas experiências. Na construção da identidade da personagem, essa marca torna-se fundamental para a compreender: Jacinta sente-se brasileira, mesmo sendo portuguesa de nascimento e tendo voltado para Portugal na idade adulta, para cuidar da mãe e tentar retomar uma ponta de sua vida que ficara em aberto.

Além de Raul, Jacinta teve mais dois filhos — Rafael e Rita — e foi casada, pela segunda vez, com o carioca Ramiro. Como se percebe, então, o romance de Inês Pedrosa traz um rol de personagens brasileiras, as quais vão tendo suas personalidades deslindadas ao longo da obra. É possível, assim, dizer que Desamparo, a despeito de se passar em Portugal, constrói uma imagem do povo brasileiro configurada por retratos, como em um jogo caleidoscópico.

Em que pese a construção consistente da narrativa e das personagens, o romance de Inês Pedrosa acaba por lançar mão de algumas das características que, de uma maneira ou de outra, sempre pairam em torno da imagem que se faz do povo brasileiro. Tome-se como exemplo a descrição que o romance faz do segundo marido de Jacinta:

Ramiro Lobo. Fiscal da Prefeitura, terno branco, gravata colorida, boa figura, com um sorriso feito de goiabada. [...] Era uma coisa... chegava a sair cedo da casa da mãe em 
Copacabana para me ver nadar na Praia do Flamengo. Ah, Ramiro, como é que você pôde me trair tanto? [...] (PEDROSA, 2015, p.18)

Com sua "boa figura", seu "terno branco" e um sorriso doce e envolvente, "feito de goiabada", Ramiro corresponde à imagem do malandro carioca dos anos 1950. O fato de ser caracterizado como fiscal da Prefeitura do Rio de Janeiro também colabora para essa construção: no imaginário brasileiro, a imagem do fiscal é, quase sempre, relacionada à de alguém que usa o cargo público para se beneficiar pessoalmente (isso pode ser visto, por exemplo, em inúmeras crônicas do jornalista Sérgio Porto, o Stanislaw Ponte Preta, publicadas entre as décadas de 1950 e 1960). Como todo malandro, o marido de Jacinta também foi incapaz de ser fiel à esposa, tendo tido várias amantes enquanto foram casados e deixando-a por uma mulher bem mais jovem.

A trajetória de Ramiro ao longo do romance reforça essa primeira caracterização. Alguns episódios, como o momento em que pede ao filho de, então, 12 anos, que falsifique uma assinatura em um cheque, ou a maneira como se comporta Jacinta e Irene, a ex-mulher e a então esposa, que estão juntas em uma reunião em sua casa, coadunam com a imagem de malandro que a primeira descrição sugere já fortemente. Ainda que essa imagem esteja adstrita a um contexto específico - a boêmia dos anos 1950 —, a maneira como Ramiro segue se comportando, seu modo perdulário de vida e sua tendência a envolver-se em negócios sobre os quais paira a sombra da dúvida, estendem esse perfil de brasileiro para os primeiros anos do século XXI, quando, aos 81 anos, a personagem morre.

Na construção do romance, uma das características que chamam atenção é o fato de que, em determinadas passagens, as palavras da personagem narradora (e são algumas ao longo da obra) explicitam o pensamento da autora a respeito de determinadas questões. A certa altura, a propósito dos negócios de Ramiro, Jacinta faz uma observação que deixa entrever como Inês Pedrosa percebe o funcionamento do sistema jurídico brasileiro (e do português):

Então correu o Brasil como vendedor da Enciclopédia Britânica, coisa prestigiada; depois começou vendendo livros de Direito para advogados, e terminou criando a sua própria editora, a que chamou o Clube do Advogado. Foi um sucesso: nos países em que a justiça é uma miragem e as leis mudam a toda a hora, como no Brasil ou em Portugal, os advogados multiplicam-se como coelhos. (PEDROSA, 2015, p. 77)

A definição do sistema jurídico brasileiro como "uma miragem", embora essa característica também seja atribuída ao sistema jurídico português, aponta para o fato de que, na visão do narrador de Desamparo, os negócios de Ramiro apenas prosperaram por conta da fragilidade da justiça no Brasil, país em que "os advogados multiplicam-se como coelhos". $\mathrm{O}$ uso dessa expressão, inclusive, é o indício de que o sistema jurídico brasileiro não funciona bem: são necessários muitos advogados para operar um sistema que não é acessível ao cidadão comum, tornando-o refém desses profissionais. 
É importante notar, ainda, que esse comentário de Jacinta sobre a justiça brasileira também reforça a composição de Ramiro Lobo como um homem que sabe se aproveitar das situações para obter sucesso - alguém que, antigamente, seria chamado de oportunista, mas hoje, certamente, receberia o rótulo de "empreendedor" - imagem que se encaixa bem no perfil de malandro com que a personagem é construída.

A religiosidade de Ramiro também é mencionada em determinado momento do romance. O ex-marido de Jacinta " [...] frequentava a umbanda. Ramiro era um orgulhoso filho de Xangô; acendia velas e oblatava garrafas de cerveja nas cachoeiras para o seu orixá" (PEDROSA, 2015, p. 80). A escolha da autora por uma religião de matriz africana para atribuir à personagem pode estar ligada à íntima conexão que existe entre as culturas africana e brasileira, uma vez que o Brasil foi o país que recebeu o maior número de africanos escravizados. Logo, uma religião de matriz africana seria representativa dessa presença.

No entanto, é fato também que a esmagadora maioria da população brasileira se declara adepta de alguma religião cristã. De acordo com o último censo do IBGE, em um universo de 190 milhões de pessoas, mais de 165 milhões declararam-se cristãs (entre católicos e protestantes), enquanto pouco mais de 500 mil pessoas disseram ser adeptas da umbanda ou do candomblé. Assim, a escolha da umbanda para ser a religião de Ramiro Lobo traz para a narrativa uma nuance de exotismo, frequentemente vinculada às religiões de matriz africana ou, em caráter mais amplo, à própria cultura africana. É bem verdade, ainda, que o Brasil é o país do sincretismo religioso, em que, frequentemente, as manifestações religiosas se misturam, o que também pode ter influenciado a escolha da autora para a religião da personagem.

Outra personagem que compõe esse caleidoscópio identitário é Jacinta Sousa, a mãe do protagonista Raul. Narradora de alguns dos primeiros capítulos da obra, Jacinta é portuguesa e viveu durante mais de cinquenta anos no Rio de Janeiro. Como já se disse, isso a coloca em uma espécie de não lugar: é "a brasileira" em Portugal, mas sempre foi "a portuguesa" no Brasil. Sobre a experiência de ser "a brasileira" em Arrifes, sua aldeia, diz a personagem:

Eu sou "a brasileira" boa da aldeia, porque sou demasiado velha para evocar os fantasmas das brasileiras sedutoras, e porque me tornei a confessora dos pecados que as portuguesas não ousam contar umas às outras. Confessora-psicóloga. Além de que gosto de cantar, e toda a gente precisa, nalgum momento, de uma canção. Essa foi sempre a força do Brasil. (PEDROSA, 2015, p. 27-28)

A fala de Jacinta denota algumas constatações a respeito da imagem que se faz da mulher brasileira em Portugal. Jacinta é a brasileira "boa da aldeia” porque já não seduz. É sabido que a imagem da mulher brasileira, desde há muito tempo, é associada a uma beleza sedutora, porque exótica. Isso aparece em várias peças publicitárias comerciais e, nas décadas de 1970 e 1980, 
em peças publicitárias governamentais da área do turismo. Quanto a isso, portanto, o romance de Inês Pedrosa apenas confirma uma descrição instaurada pelo próprio imaginário brasileiro.

É interessante, porém, a classificação que o texto dá a essas mulheres. Ao mencionar "os fantasmas das brasileiras sedutoras", a narrativa traz à baila a noção de que as mulheres brasileiras representam, em alguma medida, uma espécie de ameaça em relação às portuguesas, assombrando-as quanto ao seu poder de sedução. Essa descrição repercute a imagem que o mundo tem da mulher brasileira, mas também revela, em alguma medida, como os portugueses, particularmente, ainda olham para essa figura feminina; nesse imaginário, os homens não resistem às brasileiras, sendo por elas seduzidos, e as mulheres têm nelas, portanto, rivais a serem derrotadas.

A fala de Jacinta ainda menciona a questão da musicalidade, parte fundamental da cultura brasileira. O brasileiro é tido como um povo musical, e mais, de uma musicalidade alegre, marcada por estilos como o samba, talvez o ícone mais significativo nesse sentido. $O$ fato de a personagem atribuir a essa musicalidade a "força do Brasil" pode ser lido como a sugestão de que essa seja a sua característica mais marcante culturalmente, e que dela o brasileiro tire a força para enfrentar as situações do cotidiano.

Logo em seguida, Jacinta recorda o desfile de carnaval de que participou em 1968, pela Unidos de Vila Isabel. A narração dá detalhes sobre a fantasia e sobre o enredo, evidenciando o encantamento da personagem pela festa popular:

Em 1968 fui destaque no desfile da Escola de Samba Unidos de Vila Isabel, porque o pai dos meus filhos pertencia à direcção da Escola. Ramiro desfilava na Comissão de Frente, com as outras figuras importantes. [...] Fiz muitas fantasias para o Clóvis Bornay, o grande vencedor de inúmeros Bailes do Municipal, um homem muito especial que, como eu, venerava a Beleza acima de todas as coisas. Ele mesmo me desafiou a criar uma fantasia para mim, e lá fui eu, de Princesa Isabel, acompanhada por um séquito de escravos libertados [...]. O tema do samba-enredo parecia feito de propósito para mim: Quatro séculos de modas e costumes. Ainda me lembro da letra [...]. Um samba lindo, do grande Martinho da Vila, que eu tive a alegria de conhecer. (PEDROSA, 2015, p. 28-29).

Uma das manifestações culturais brasileiras mais conhecidas no mundo, os desfiles das escolas de samba, impregnam o imaginário a respeito do país, tornando-se quase sinônimo de cultura brasileira. Não há como escapar desta constatação: junto com o futebol, o carnaval carioca forma o rosto do Brasil para o mundo há décadas, mesmo que outras manifestações culturais existam e ainda que outros esportes sejam praticados no país.

Além disso, a imagem do carnaval carioca, historicamente, esteve associada à malandragem, da qual Ramiro fazia parte. Ainda hoje, os componentes das velhas guardas das escolas de samba desfilam com ternos brancos e gravatas coloridas, exatamente como Ramiro se vestia, segundo a descrição do romance. 
Em um romance que se passa parcialmente no Rio de Janeiro, no qual a personagem vive por mais de cinquenta anos, torna-se quase inevitável a referência ao carnaval. No entanto, também é inevitável pensar que essa referência acaba por fixar a visão estereotipada que se tem do Brasil, como "o país do carnaval" e da malandragem. Ainda que a malandragem de Ramiro e o desfile da Vila Isabel estejam localizados em um recorte específico de tempo e espaço - trata-se do Rio de Janeiro das décadas de 1950 e 1960 - , o fato é que o Brasil continua sendo visto dessa maneira pelo mundo, o que justificaria a opção da autora por inserir esses dois temas no romance.

Outro aspecto que o romance trata e que está relacionado à maneira como os portugueses veem os brasileiros aparece em uma reflexão de Jacinta sobre a situação profissional de Raul:

Culpado, como eu, de ter duas pátrias e não encontrar compatriotas em nenhuma. Culpado de estar pobre, num país de pobres, e com o sotaque errado. O "brasileiro" em Portugal. Uma das empresas de arquitectura em que tentou trabalhar respondeu-lhe que já tinham excesso de brasileiros. (PEDROSA, 2015, p.27)

Essa passagem do romance aponta para um fato: os brasileiros que vão para Portugal em busca de uma oportunidade são vistos como uma espécie de estorvo. Raul não encontrava emprego porque tinha "o sotaque errado", o que dá a entender que o fato de ser brasileiro pesava mais do que qualquer outra qualificação profissional que pudesse ter. Isso é reforçado pela declaração de uma das empresas, de que tinham "excesso de brasileiros", como se houvesse uma cota de brasileiros a ser tolerada na empresa. Isso tudo demostra que, ainda hoje, a ideia de "pátrias irmãs" não é exatamente uma realidade na prática.

É preciso notar, entretanto, que o mesmo se dá no Brasil. Jacinta já havia dito que, aqui, era "a portuguesa", e essa passagem mostra que o mesmo acontece com Raul, que tinha "duas pátrias" e não encontrava "compatriotas em nenhuma". Esse trecho enseja uma constatação incômoda: a despeito da autoimagem do brasileiro como um povo hospitaleiro, não é assim que os portugueses veem a questão. Ao dizer que Raul não tinha compatriotas no Brasil, como em Portugal, coloca-se em xeque a noção de que os portugueses não enfrentem nenhum tipo de resistência na ex-colônia. Nesse sentido, é preciso lembrar que há, também, uma visão estereotipada dos portugueses no Brasil: para os brasileiros, os portugueses são "burros”, e essa é uma visão que se mantém ainda hoje.

No entanto, o romance aponta para uma outra questão relevante, no que diz respeito à presença dos brasileiros em Portugal. Ao comentar sobre a maneira como conheceu Laís, um de seus amores, o arquiteto Raul faz a seguinte declaração:

Publicitários, informáticos, arquitectos, dentistas e agentes imobiliários, levas e mais levas de "brasucas", entre habilitados, curiosos, aventureiros, ou no mínimo esforçados, entupiam o Aeroporto da Portela desde o final dos anos oitenta. [...] A economia estava 
em expansão e necessitava de cérebros. Só perto da virada do século desovaria uma outra leva de brasileiros, menos qualificados, para alimentar o gigantesco canteiro de obras em que o país se havia tornado. (PEDROSA, 2015, p. 175)

Ao contrário do que acontece no Brasil em relação aos portugueses, essa passagem do romance denota que houve uma presença maciça de brasileiros no mercado de trabalho português desde a década de 1990. Ao declarar que a economia "estava em expansão e necessitava de cérebros", o romance aponta para a recepção de brasileiros para funções mais sofisticadas, ao passo que, ao final da década, os brasileiros foram para Portugal trabalhar em funções mais "braçais".

Quando se juntam as visões que o romance apresenta sobre a presença dos brasileiros em Portugal, chega-se a uma conclusão incômoda: os "brasucas" são uma espécie de "mal necessário" para a economia portuguesa, mas não são exatamente bem-vindos para morar no país. Essa constatação reverbera uma série de relatos de xenofobia contra brasileiros em Portugal (um exemplo foi o caso das pedras para atirar em "zucas", na Faculdade de Direito da Universidade de Lisboa, em abril de 2019) e ajuda a trazer à tona os preconceitos que existem na relação entre brasileiros e portugueses. Pode-se dizer, portanto, que, em certa medida, o romance de Inês Pedrosa, ao criar relatos como os de Jacinta e Raul, problematiza uma relação histórica, a qual, como o romance deixa entrever, não tem sido tão tranquila quanto se imagina.

Outro aspecto da representação que se faz do brasileiro em Desamparo é a questão da sexualidade. A certa altura do romance, o arquiteto Raul comenta sobre sua juventude: "Nos tempos de faculdade, pegava namoradas mesmo sem querer, acumulando as oficiais com as de ocasião. No Brasil, quando não se tem muito, sempre temos como diversão o próprio corpo"(PEDROSA, 2015, p. 55).

A declaração de Raul aponta para uma forma de masculinidade frequentemente associada ao homem brasileiro. Ao dizer que "pegava namoradas mesmo sem querer", a personagem aponta para uma masculinidade que se afirma pelo número de conquistas, ainda que isso não implique nenhuma forma de interesse mais profundo. Nesse sentido, o próprio uso do verbo "pegar" para indicar as relações que estabelecia já denota essa forma de masculinidade, de acordo com a qual o "pegador" (expressão bastante usada no Brasil para denotar o homem que tem vários relacionamentos, quase sempre ao mesmo tempo) deve, mesmo "sem querer", ter o maior número possível de relacionamentos.

Se, em um primeiro momento, o leitor pode atribuir essa característica a Raul apenas, a sequência do texto amplia o alcance da descrição dessa masculinidade, ao dizer que, no Brasil, o corpo é fonte de diversão. Além da discussão acerca dessa forma de masculinidade, a passagem enseja uma reflexão sobre a representação do brasileiro em relação à forma como exerce sua sexualidade.

A declaração de Raul dá margem a uma leitura da sexualidade do brasileiro que não necessariamente corresponde à realidade. Ao dizer que, no Brasil, "quando não se tem muito, 
sempre temos como diversão o próprio corpo “, o texto sugere que o exercício da sexualidade seja, de alguma maneira, relacionado à pobreza, o que, de fato, é um estereótipo corrente no imaginário do brasileiro (havia, ou ainda há, uma piada corrente no Brasil sobre as pessoas mais pobres que têm muitos filhos, dizendo que isso acontece porque elas não têm televisores em casa). Em que pese o fato de que, no romance, é um brasileiro a declarar isso, deve-se levar em conta que se trata de uma composição de autoria portuguesa, o que sugere o fato de que, para os portugueses, é essa a imagem que se tem da sexualidade dos brasileiros.

Outra passagem do romance que está diretamente ligada à discussão sobre a imagem que se tem da sexualidade do brasileiro está na descrição de Jaciara, pernambucana que Raul conhece em um bar e com quem se envolve emocionalmente:

Porém, após os primeiros três meses brigávamos com alguma frequência, e sempre pelo mesmo motivo: sexo. Jaciara era mais do que uma nordestina vulcânica; um incêndio. Apesar de pequenina, possuía um órgão sexual proeminente, do qual se orgulhava: "Eu sou muito "periquituda", brincava. Para ela, uma relação de amor baseava-se em transar todos os dias [...]. (PEDROSA, 2015, p. 116)

Alguns aspectos da descrição de Jaciara chamam atenção exatamente por apontar para uma sexualidade exacerbada, a ponto de isso provocar brigas entre ela e Raul. A pernambucana é descrita como "mais do que uma nordestina vulcânica; um incêndio", expressão que sugere serem as mulheres nordestinas todas "vulcânicas", e Jaciara, mais do que todas as outras, "um incêndio". Tal caracterização revela uma imagem acerca da mulher brasileira correspondente àquela que, conforme já foi dito, tem sido vendida ao mundo há algum tempo, a da brasileira fogosa, que se notabiliza exatamente por essa hipersexualidade. Essa imagem torna-se ainda mais explícita com o uso do termo "periquituda", para referir-se ao órgão sexual de Jaciara. $\mathrm{O}$ detalhe anatômico da personagem aparece como um amplificador da imagem de mulher hipersexualizada, frequentemente atribuída à mulher brasileira no exterior.

Além disso, Raul declara que, para a ex-namorada, "uma relação de amor baseava-se em transar todos os dias", expressão que reforça a ideia de uma sexualidade exagerada e, de certo modo, representa, em relação à sociedade, uma espécie de inversão de valores, uma vez que, de maneira machista, é normalmente ao homem que se atribui a necessidade mais frequente de relações sexuais.

Nesse sentido, é preciso que se note, a presença de uma personagem como Jaciara traz para o romance uma temática relevante, especialmente para as mulheres: o exercício da sexualidade não é exclusividade dos homens, sendo parte tão essencial do universo feminino quanto é para o masculino. No entanto, a descrição da personagem acaba por reforçar uma imagem que, de fato, se tem perpetuado por décadas, a da mulher brasileira sempre disposta ao sexo e, a rigor, hipersexualizada. 
Por fim, é preciso trazer à baila a caracterização de Raul, o protagonista da obra. Terceiro filho de Jacinta e Ramiro, foi ele o único a ficar ao lado da mãe durante a velhice dela. Brasileiro que escolheu viver em Portugal, sente-se mais português do que brasileiro e, de certa forma, foge ao estereótipo do homem brasileiro: sensível e, mesmo que negue, romântico, procura nas mulheres a companheira perfeita, que lhe complete a alma. Encontra essa companheira na portuguesa Clarisse, jornalista cuja trajetória de vida acabou por levar a Arrifes, na tentativa de fugir de um passado tormentoso.

A caracterização de Raul acontece ao longo do romance, nos capítulos narrados por ele, mas também pela visão de Clarisse, narradora de alguns dos capítulos da obra. Raul é um homem inseguro, frustrado com a própria profissão e com ter de a abandonar, por necessidade. Diferentemente do pai e do irmão Rafael, é um homem íntegro, cuja conduta se distancia da imagem do brasileiro que busca levar vantagem em tudo. Em grande medida, Raul contraria, portanto, o perfil de brasileiro que é instituído no início do romance, com a descrição que Jacinta faz de Ramiro. A imagem do malandro, que vive de golpes e em busca de oportunidades para o sucesso fácil, dá lugar à do trabalhador que se vê levado a deixar seu próprio país em busca de oportunidades.

Assim, a caracterização do brasileiro em Desamparo oscila entre o reforço a certos estereótipos, em torno dos quais gira a imagem (e a autoimagem) do brasileiro no mundo, e a contradição a esses estereótipos. Se o Brasil, no romance de Inês Pedrosa, é a terra dos malandros, do carnaval e das mulheres sedutoras, também é o país de pessoas como Raul, que não abrem mão de seus valores e têm uma conduta ética, que não lhes permite levar vantagens indevidas. De certa forma, portanto, a obra acaba por problematizar a visão que os próprios portugueses têm dos brasileiros, trazendo à tona exemplos de comportamento que não correspondem aos estereótipos.

\section{Referências}

LUCAS, Isabel. Portugal e Brasil: orgulho e preconceito entre duas literaturas. Público, Lisboa, Caderno Ípsilon, 3 abr. 2015. Disponível em: https://www.publico. pt/2015/04/03/culturaipsilon/noticia/portugal-e-brasil-orgulho-e-preconceito-entre-duasliteraturas-1690391. Acesso em: 30 jul. 2019.

PEDROSA, Inês. Desamparo. 2 ed. Lisboa: Dom Quixote, 2015.

\section{Minicurrículo}

Mauro Dunder é mestre e doutor em Letras (Literatura Portuguesa) pela Universidade de São Paulo. Atualmente, é professor adjunto do Departamento de Letras da Universidade Federal do Rio Grande do Norte, onde lidera o Núcleo de Estudos Portugueses e o Grupo de Pesquisa "Literatura de Autoria Feminina". 